\title{
Kernos
}

Revue internationale et pluridisciplinaire de religion grecque antique

12| 1999

Varia

\section{Kentron, 14 (1998) : Dionysos et l'énigme des Bacchantes}

Isabelle Tassignon

\section{(2) OpenEdition}

\section{Journals}

Édition électronique

URL : http://journals.openedition.org/kernos/736

DOI : 10.4000/kernos.736

ISSN : 2034-7871

\section{Éditeur}

Centre international d'étude de la religion grecque antique

Édition imprimée

Date de publication : 1 janvier 1999

Pagination : 310-311

ISSN : 0776-3824

\section{Référence électronique}

Isabelle Tassignon, «Kentron, 14 (1998): Dionysos et l'énigme des Bacchantes », Kernos [En ligne], 12 | 1999, mis en ligne le 13 avril 2011, consulté le 21 septembre 2020. URL : http:// journals.openedition.org/kernos/736 ; DOI : https://doi.org/10.4000/kernos.736 
pas partie du sanctuaire de Déméter. La discussion vaut la peine d'être signalée car il n'est pas indifférent pour l'étude du culte de la déesse de savoir si oui ou non Zeus Meilichios était honoré dans son sanctuaire, et, de même, si le lieu d'enfouissement des plaques de défixions en faisait partie ou non. Or, non seulement V. Hinz ne fait pas la moindre allusion au problème, mais encore, sa position à ce sujet n'est pas claire. En effet, elle n'évoque Zeus Meilichios que dans la synthèse finale sur le sanctuaire de la Malophoros, et non au moment de sa description proprement dite. Mais en même temps, les defixiones sont présentées comme issues du complexe, et, de même, le plan peut laisser croire que le témenos de Zeus en fait partie. Un autre point concerne les pinakes du sanctuaire de Perséphone à Locres, ces fameuses plaques illustrées de scènes religieuses, qui constituent notre principale source d'informations sur le culte locrien de la déesse (à ce sujet, voir p. ex., Chr. Sounvinou-Inwood, Persephone and Apbrodite at Locri: A Model for Personality Definitions in Greek Religion, in JHS, 98 [1978], p. 101-121). Étant donné l'intérêt de ces documents et les problèmes d'interprétation qu'ils soulèvent, une étude à leur sujet avait toute sa place dans un ouvrage tel que celui-ci. Aussi le lecteur est-il très surpris de n'y voir consacrées que quelques lignes et de n'en trouver aucune illustration. Signalons enfin une question d'interprétation. L'A. considère que la standardisation des statuettes de terre cuite apparaissant au $\mathrm{v}^{e} s$. pourrait signifier que, tout comme les Thesmophories d'Athènes, les fêtes siciliennes étaient à cette époque réservées aux citoyennes (p. 227). Si le fait n'est pas impossible en lui-même, surtout dans les circonstances politiques et sociales du moment ( $c f$. p. 226-227), cependant, on ne comprend pas bien en quoi l'uniformisation des figurines votives le suggère.

Ces critiques ne doivent pas occulter les qualités de l'ouvrage, qui deviendra certainement une référence pour le culte de Déméter et de Koré.

Véronique Suys (Université Catholique de Louvain Facultés universitaires Saint-Louis)

Kentron. Revue du monde antique et de psycbologie bistorique, 14 (1998)= Actes des travaux du Groupe de Recherche "Mythe, bistoire et psychanalyse" sur Dionysos et l'énigme des Bacchantes (1995-1998). ISSN : 07650590 .

Ainsi qu'en témoigne la bibliographie dressée par G. Karsai en fin d'ouvrage, la littérature scientifique suscitée par les Bacchantes d'Euripide est particulièrement abondante et n'a cessé de crôitre ces dernières années. Fruit des travaux du groupe de recherches Mytbe, Histoire et Psychanalyse, cette publication comptera dans l'histoire du dionysisme tant elle renouvelle, par l'originalité de ses perspectives pluridisciplinaires, l'étude du texte d'Euripide. Plusieurs contributions sont d'ailleurs consacrées au long parcours suivi par Les Bacchantes, depuis sa création, en 405 (Fr. Jouan), jusqu'à sa survivance au Moyen Âge dans le Christos Pascbôn (J.-M. Mathieu), et sa toute récente mise en scène par I. Bergman (P. Legangneux).

Fr. Jouan, dans Une introduction au mythe des Bacchantes, montre comment s'est constituée la tragédie d'Euripide, et quelles furent ses principales voies de transmission philologique. Dans une même optique, l'article de J. Bottéro souligne l'existence d'éléments similaires dans un mythe mésopotamien récemment découvert et traduit qui, sur le célèbre modèle de la Descente d'Ishtar aux Enfers, relate la catabase de Nin-gesh-zi-da, probablement un dieu du vin; J. Bottéro ouvre ainsi la voie à la prudente comparaison avec les mythes proche-orientaux. 
On s'étonne un peu de ne voir exploitées dans aucune des contributions rassemblées ici les allusions du texte d'Euripide aux origines lydiennes du dieu. L'étude des textes et la comparaison des structures mythiques qui les soustendent sont les pistes empruntées par A. Moreau pour aborder le problème crucial de la signification initiatique du sacrifice de Penthée: dans la ligne de diverses interprétations récemment proposées du sacrifice dionysiaque ${ }^{1}$, l'auteur renouvelle la lecture du sacrifice du bouc-émissaire en le rapprochant d'autres sacrifices à caractère initiatique, tels ceux d'Actéon et d'Orphée, et conclut à l'existence d'une initiation manquée de Penthée dans les Bacchantes. Enfin, C. Jouanno s'est livrée à une étude de la chronique de J. Malalas, réinterprétation moralisante et politique de l'histoire de Dionysos et de Penthée.

$\grave{A}$ ces approches relativement classiques s'opposent les démarches de chercheurs venus d'autres horizons; l'iconographie, par exemple, permet à M. HalmTisserand de dresser un catalogue complet des scènes illustrant la mise à mort de Penthée et son démembrement par les femmes de Thèbes qui renouvelle sensiblement, sur ce point précis, le catalogue jadis établi par H. Philippart ${ }^{2}$. L. Beck Chauvard, comparant l'épiphanie dionysiaque des Baccbantes à l'épiphanie du dieu auprès d'Ariane, souligne les éléments communs aux deux apparitions, mais aussi leurs profondes différences. Dans une optique davantage philosophique, S. Vilatte a tenté de montrer, en une comparaison éclairante, dans quelle mesure le dionysisme peut constituer une clé de lecture du socratisme puisque c'est un fidèle du dionysisme qui se lit en filigrane du personnage de Socrate dans le Phèdre, fidèle tout épris d'un dionysisme sage et chaste tel que le prônent les bacchantes. Dans Dionysos et le crucifié, B. Fricker met en évidence les phénomènes présidant à la resémantisation des symboles du dionysisme et du christianisme que sont le thyrse et la croix. La place des Bacchantes comme pièce destinée au théâtre est abordée par J. Chemouni; et ce sont les récits comme mode d'expression qui sont mis en exergue dans l'article de M. Lacore; enfin, B. Deforge montre combien, en suggérant le démembrement de Penthée par le biais du récit, Euripide va loin dans la «monstration » de la mort.

Parce qu'elle touche aux universaux constitutifs de la personnalité humaine, cette tragédie qui met aux prises un dieu et un roi, qu'unissent aussi des liens de parenté, mais surtout une mère et son fils, est passible d'une interprétation psychanalytique; M.-J. Bataille, dans «Pulsions " de vie et "pulsions » de mort dans les Bacchantes, en décortique les ressorts intimes, en proposant du fatal affrontement une lecture freudienne. De trop nombreuses coquilles émaillent cependant assez tristement plusieurs articles de ce livre enthousiasmant qui révèle quel bénéfice un texte aussi connu que les Bacchantes peut retirer d'une approche interdisciplinaire.

Isabelle Tassignon (Université de Liège)

Fernando Wulf f Alonso, La Fortaleza asediada. Diosas, Héroes y Mujeres poderosas en el mito griego, Salamanca, Ediciones Universidad, 1997. 1 vol. $17 \times 24 \mathrm{~cm} .357$ p. (Acta Salmanticensia. Estudios bistóricos $\&$ geogräficos, 105). ISBN : 84-7481-813-6.

1 D. OBbINk, Dionysus Poured Out: Ancient and Modern Tbeories of Sacrifice and Cultural Formation, dans T.H. Carpenter et C.A. Faraone (éds), Masks of Dionysus, IthacaLondres, 1993, p. 65-88; R. SEAFORD, Reciprocity and Ritual, Oxford, 1994.

2 H. Philippart, L'iconograpbie des « Bacchantes » d'Euripide, Paris, 1930. 